\section{Excipients as Potential Agents of Anaphylaxis in Vaccines: Analyzing the Formulations of Currently Authorized COVID-19 Vaccines}

Caballero ML, Quirce S

Department of Allergy, La Paz University Hospital, IdiPAZ, Madrid, Spain

J Investig Allergol Clin Immunol 2021; Vol. 31(1): 92-93 doi: $10.18176 /$ jiaci.0667

Key words: Allergy. Anaphylaxis. Coronavirus. COVID-19. Immediate drug hypersensitivity reaction. Excipient. Pharmaceutical excipients. Vaccine.

Palabras clave: Alergia. Anafilaxia. Coronavirus. COVID-19. Reacción de hipersensibilidad inmediata a medicamentos. Excipiente. Excipientes farmacéuticos. Vacuna.

\section{To the Editor:}

The aim of this letter is to provide a brief update on excipients in vaccines as potential causes of immediate hypersensitivity reactions (IHRs), with a special focus on the excipients present in the formulations currently used for vaccination against coronavirus disease (COVID-19), which is produced by the severe acute respiratory syndrome coronavirus 2 (SARS-CoV-2).

IHRs to vaccines are frequently caused by the excipients contained in their formulations. In some cases, previous sensitization to an excipient is the cause of the reaction, as shown in a study to confirm the relationship between systemic allergic reactions to vaccines and the presence of antigelatin $\mathrm{IgE}$ in children with allergy to gelatin-containing vaccines [1]. Sakaguchi et al [2] reported the cases of 4 children with IgEmediated systemic reactions to gelatin in a varicella vaccine, where 2 of the children experienced anaphylaxis and the other 2 developed generalized urticaria after the vaccination [2]. The excipient polysorbate 80 (PS80) is also involved in IHRs to vaccines. A case of anaphylaxis was reported after the third administration of quadrivalent human papillomavirus vaccine (Gardasil), which contains PS80 [3].

Polysorbates are polyethylene glycol (PEG) derivatives, specifically PEG sorbitans [4]. PEG, with the formula $\mathrm{H}(\mathrm{OCH} 2 \mathrm{CH} 2) \mathrm{nOH}$ (PubChem CID 174, https://pubchem. ncbi.nlm.nih.gov/compound/1_2-Ethanediol), is synthesized by polymerization of ethylene oxide. The resulting polymers vary in chain length and molecular weight. In addition to polysorbates, PEG and all its derivatives - including PEG ethers (laureths, ceteths, ceteareths, oleths), PEG fatty acid esters (PEG laurates, dilaurates, stearates, and distearates), PEG amine ethers, PEG castor oils, PEG-propylene glycol copolymers (poloxamers), and PEG soy sterols-are present as excipients in many pharmaceutical and cosmetic products [4] and have been identified as the culprit agents in a large number of reported IHRs [5]. PEGs have also been used in polymer-based drug delivery. The process of PEGylation involves binding of PEGs to systemic drugs to increase molecular weight, prolong circulation time, and shield the drug from the immune system by preventing opsonization. Thus, PEG hypersensitivity should encompass PEGs, structurally similar PEG derivatives, and PEGylated drugs [4].

The 3 COVID-19 vaccines that are currently being administered with Emergency Use Authorization (EUA) are Pfizer-BioNTech (BNT162b2), Moderna (mRNA-1273), and AstraZeneca (ChAdOx1-S [recombinant]). The Table shows the composition of the vaccines and the full list of their excipients.

The COVID-19 mRNA vaccine BNT162b2 is a highly purified single-stranded, 5'-capped messenger RNA (mRNA) produced by cell-free in vitro transcription from the corresponding DNA templates that encodes the viral spike protein of SARS-CoV-2 and is embedded in lipid nanoparticles (LNPs) (https://www.gov.uk/government/publications/ regulatory-approval-of-pfizer-biontech-vaccine-for-covid-19/ information-for-healthcare-professionals-on-pfizerbiontechcovid-19-vaccine). This vaccine contains PEG 2000, which is a potential cause of IHRs.

The Moderna (mRNA-1273) COVID-19 vaccine contains a synthetic mRNA encoding the prefusion stabilized spike protein of SARS-CoV-2 that is formulated in LNPs (https:// www.fda.gov/media/144434). It also contains PEG 2000 and tromethamine (PubChem CID 6503, https://pubchem.ncbi. nlm.nih.gov/compound/2-Amino-2-hydroxymethyl-propane1-3-diol), which can potentially cause IHRs. Tromethamine or trometamol (synonym) was recently reported to cause anaphylaxis in a patient receiving gadoteridol (Prohance), a gadolinium-based contrast agent [6].

The AstraZeneca vaccine (ChAdOx1-S [recombinant]) is based on a recombinant, replication-deficient chimpanzee adenovirus vector encoding the SARS-CoV-2 spike glycoprotein, which is produced in genetically modified human embryonic kidney 293 cells (https://www.gov.uk/government/publications/ regulatory-approval-of-covid-19-vaccine-astrazeneca). The potential cause of IHRs in this vaccine is PS80.

Two of the above vaccines, Pfizer-BioNTech (BNT162b2) and Moderna (mRNA-1273), are formulated in LNPs or PEGylated liposomes (PEGlips). PEGlips are artificial phospholipid vesicles that have proven useful in stabilizing drugs and improving their pharmacological properties [7]. In the case of these COVID-19 vaccines, the labile nature of mRNA means that it can be preserved in LNP-based formulations [8].

In general, 2 aspects related to excipients should be taken account before the administration of any vaccine or medication. First, IHRs to unrelated products with a common excipient have been reported [5]. For example, a patient experienced anaphylaxis after the intake of a laxative solution during bowel preparation 
Table. Composition of the 3 COVID-19 Vaccines Currently Being Administered With Emergency Use Authorization

\begin{tabular}{|c|c|c|}
\hline Pfizer-BioNTech (BNT162b2) & Moderna (mRNA-1273) & $\begin{array}{l}\text { AstraZeneca } \\
\text { (ChAdOx1-S [recombinant]) }\end{array}$ \\
\hline $\begin{array}{l}\text { mRNA encoding the viral spike } \\
\text { protein of SARS-CoV-2 virus }\end{array}$ & $\begin{array}{l}\text { Synthetic } m \text { (mRNA) encoding the prefusion } \\
\text { stabilized spike glycoprotein of } \\
\text { SARS-CoV-2 virus }\end{array}$ & $\begin{array}{l}\text { Recombinant, replication-deficient } \\
\text { chimpanzee adenovirus vector encoding } \\
\text { the SARS-CoV-2 spike glycoprotein }\end{array}$ \\
\hline $\begin{array}{l}\text { ALC-0315 = (4-hydroxybutyl) } \\
\text { azanediyl)bis (hexane-6,1-diyl) } \\
\text { bis(2-hexyldecanoate) }\end{array}$ & Lipid SM-102 & L-Histidine \\
\hline $\begin{array}{l}\text { ALC-0159 = 2-[(polyethylene glycol) } \\
-2000]-N, N-d i t e t r a d e c y l a c e t a m i d e^{\mathrm{a}}\end{array}$ & $\begin{array}{l}\text { 1,2-dimyristoyl-rac-glycero3-methoxypolyethylene } \\
\text { glycol-2000 [PEG2000-DMG] }\end{array}$ & L-Histidine hydrochloride monohydrate \\
\hline $\begin{array}{l}\text { 1,2-Distearoyl-sn-glycero-3- } \\
\text { phosphocholine }\end{array}$ & Cholesterol & Magnesium chloride hexahydrate \\
\hline Cholesterol & 1,2-distearoyl-snglycero-3-phosphocholine [DSPC] & Polysorbate $80^{\mathrm{a}}$ \\
\hline Potassium chloride & Tromethamine $^{\mathrm{a}}$ & Ethanol \\
\hline Potassium dihydrogen phosphate & Tromethamine hydrochloride & Sucrose \\
\hline Sodium chloride & Acetic acid & Sodium chloride \\
\hline $\begin{array}{l}\text { Disodium hydrogen phosphate } \\
\text { dihydrate }\end{array}$ & Sodium acetate & Disodium edetate dihydrate \\
\hline Sucrose & Sucrose & \\
\hline
\end{tabular}

These excipients are potential causes of immediate hypersensitivity reactions, as they have been involved in previously reported reactions.

and reactions after applying a sunscreen and using toothpaste, both of which were PEG-containing products [9]. Second, there is a real possibility of cross-reactivity between PEGs and their derivatives [4]. Therefore, it is important to check all the excipients present in the formulation of a vaccine and to determine in which other products they may be present, including medications, foods, and cosmetics, in order to perform an exhaustive search for possible previous causes of hypersensitivity.

In conclusion, vaccine excipients, some of which are present in the novel SARS-CoV-2 vaccines authorized to date, can give rise to hypersensitivity reactions. A thorough clinical history should be obtained in the case of patients with a previous history of allergic reactions to vaccines or excipients in medications and cosmetics. In addition, an appropriate allergological assessment should be performed to prevent sudden hypersensitivity reactions to vaccines.

\section{Funding}

The authors declare that no funding was received for the present study.

\section{Conflicts of Interest}

Dr Quirce reports personal fees and nonfinancial support from GSK, AstraZeneca, Sanofi, Novartis, Mundipharma, Teva, and Allergy Therapeutics outside the submitted work.

Dr Caballero declares that she has no conflicts of interest.

\section{References}

1. Sakaguchi $M$, Nakayama $T$, Inouye $S$. Food allergy to gelatin in children with systemic immediate-type reactions, including anaphylaxis, to vaccines. J Allergy Clin Immunol. 1996;98:1058-61.
2. Sakaguchi M, Yamanaka T, Ikeda K, Sano Y, Fujita H, Miura T, et al. IgE-mediated systemic reactions to gelatin included in the varicella vaccine. J Allergy Clin Immunol. 1997;99:263-4.

3. Badiu I, Geuna M, Heffler E, Rolla G. Hypersensitivity reaction to human papillomavirus vaccine due to polysorbate 80 . BMJ Case Rep. 2012;2012:bcr0220125797.

4. Wenande E, Garvey L. Immediate-type hypersensitivity to polyethylene glycols: a review. Clin Exp Allergy. 2016;46:907-22.

5. Caballero ML, Quirce S. Immediate hypersensitivity reactions caused by drug excipients: A Literature Review. J Investig Allergol Clin Immunol. 2020;30:86-100.

6. Lukawska J, Mandaliya D, Chan AWE, Foggitt A, Bidder T, Harvey J, et al. Anaphylaxis to trometamol excipient in gadolinium-based contrast agents for clinical imaging. J Allergy Clin Immunol Pract. 2019;7:1086-7.

7. Zamboni WC. Concept and clinical evaluation of carriermediated anticancer agents. Oncologist. 2008;13:248-60.

8. Kim H, Park Y, Lee JB. Self-assembled Messenger RNA Nanoparticles (mRNA-NPs) for Efficient Gene Expression. Sci Rep. 2015;5:12737.

9. Shah S, Prematta T, Adkinson NF, Ishmael FT. Hypersensitivity to polyethylene glycols. J Clin Pharmacol. 2013;53:352-5.

Manuscript received January 11, 2021; accepted for publication January 12, 2021.

\section{María Luisa Caballero}

Department of Allergy

La Paz University Hospital, IdiPAZ

Paseo de la Castellana, 261

28046 Madrid, Spain

E-mail: mlcsoto@hotmail.com 